Acta Theriologica $42(2):$ 179-188, 1997.

PL ISSN 0001-7051

\title{
Prey selection of the least weasel Mustela nivalis in the laboratory
}

\author{
Pirjo PEKKARINEN and Jari HEIKKILÄ
}

Pekkarinen P. and Heikkilä J. 1997. Prey selection of the least weasel Mustela nivalis in the laboratory. Acta Theriologica 42: 179-188.

Prey individuals representing the bank vole Clethrionomys glareolus and the field vole Microtus agrestis were presented in pairs to male and female least weasels Mustela nivalis Linnaeus, 1766 in the laboratory. The voles were placed in two randomly selected boxes out of 8 boxes, which were connected to an arena housing the weasel. For each trial we recorded the finding, killing and eating order of the two prey individuals. Male weasels tended to kill bank voles before field voles, and female weasels preferred to eat the bank vole first. Both sexes selected juvenile bank voles as the first prey to eat.

Department of Ecology and Systematics, Division of Population Biology, P.O. Box 17 (Arkadiankatu 7), FIN-00014 University of Helsinki, Finland

Key words: Mustela nivalis, Clethrionomys, Microtus, prey selection, food preference

\section{Introduction}

The least weasel Mustela nivalis Linnaeus, 1766 is a highly specialized predator of small rodents, with a particular preference for Microtus voles (Rubina 1960, Day 1968, Erlinge 1974, Moors 1975, Tapper 1979, Henttonen 1987, King 1989, Korpimäki et al. 1991, Korpimäki 1993). The diet of the least weasel may nonetheless vary substantially according to the species composition of the small rodent community in different regions and in particular seasons. For example, in Wytham Wood in Britain, common weasels preyed mostly on bank voles Clethrionomys glareolus (King 1989), and in the Białowieża forest, Poland, the diet of least weasels consisted entirely of the bank vole and the yellow-necked mice Apodemus flavicollis (Jędrzejewski and Jędrzejewska 1993). In these cases Microtus voles were scarce or absent. The proportion of "alternative" prey in weasels' diet, mainly passerine bird nestlings and young rabbits, has been shown to vary according to the abundance of Microtus voles in the course of the season (Day 1968, Walker 1972, Tapper 1976, Korpimäki et al. 1996). Most observations on the interactions between Microtus voles and least weasels, however, originate from agricultural areas, which are suitable habitat for Microtus but not for Clethrionomys voles. King (1989) has pointed out that most British weasels actually live on farmlands. The vole species assemblage in Finland includes 10 species of microtine rodents, 
including four Microtus and three Clethrionomys species. In addition, one species of Lemmus, Myopus and Arvicola occur in Finland. Among the remaining small mammals, Sorex and Neomys shrews (6 species) and Apodemus and Micromys mice are common enough to serve as alternative prey to many predators of rodents (Hanski and Henttonen 1996). Small mustelids, however, dislike shrews (Korpimäki and Norrdahl 1989), and the numbers of mice in the diet of weasels have been shown to be low (Korpimäki et al. 1991). Of the 10 microtine species, the two most common and widely distributed species are the field vole Microtus agrestis and the bank vole Clethrionomys glareolus (Myllymäki 1972, Siivonen and Artimo 1972). The two species generally occur in the same areas, as the landscape is a small-scale mosaic of agricultural land ( $8 \%)$ and forested land $(76 \%$; Kytömäki and Kankaanrinta 1994). In this respect situation in most parts of Finland is different from that in eg southern Sweden and Britain, where the agricultural land dominates the landscape. Nonetheless, field observations generally support the significance of Microtus in the diet of weasels also in Finland. In western Finland least weasels use much more Microtus voles than bank voles (Korpimäki et al. 1991, Korpimäki 1993, Norrdahl and Korpimäki 1993). Henttonen (1987) has suggested that reproduction of least weasels in northern Fennoscandia greatly depens on the availability of Microtus voles.

Jędrzejewska and Jędrzejewski (1990) and Jędrzejewski and Jędrzejewska $(1990,1992)$ have reported several kinds of behavioural changes in the bank vole associated with increased risk of predation by weasels. These behavioural changes apparently improve bank voles' chances of escaping the predator. The presence of a weasel or a stoat slowed down maturation of captive young Clethrionomys voles (Heikkilä et al. 1993), which may represent an adaptive response, assuming that breeding females and juveniles are especially vulnerable to predation, and that high predation pressure will not last for a very long time. Clethrionomys voles do not reach equally high densities as Microtus, which should decrease the predation pressure on the former, as weasels seek for high-density prey patches in the wild (Hanski and Henttonen 1996). All these observations raise questions about the "intrinsic" prey preference by weasels. Microtus may be "preferred" in the field only because they are clumpier, breed more predictably, and attain higher densities than Clethrionomys. Perhaps weasels actually prefer Clethrionomys as a prey, other things being equal, which might even explain, to some extent at least, the suite of behaviours that help reduce predation pressure on Clethrionomys in the field.

Only a few studies have been conducted on food selection and "intrinsic" preference of least weasels in captivity. In Virginia, Derting (1989) investigated the influence of prey type (species, age) and some behavioural characteristics (aggressiveness, activity) on prey selection of a least weasel, using Peromyscus and Microtus as two prey types. Derting (1989) observed weasels to prefer smaller, inactive, and nonaggressive prey individuals. In southern Sweden, Erlinge et al. (1974) and Erlinge (1975) studied the hunting behaviour and prey selection of 
least weasels in enclosures. In their experiments they found no difference in the preference of least weasels between C. glareolus, M. agrestis and Apodemus sylvaticus, but an avoidance of the common shrew Sorex araneus. Bank voles were taken, however, most often in the beginning of the trials (Erlinge et al. 1974).

Given this limited information on prey selection in captivity, and being aware of the importance of Microtus voles in the diet of least weasels in the field in particular, we have conducted a series of arena experiments in the laboratory to test the prey choice and preference of Finnish least weasels provided with Microtus and Clethrionomys voles and with individuals of different ages.

\section{Material and methods}

Prey individuals representing the bank vole $C$. glareolus and the field vole $M$. agrestis were offered in pairs to a weasel in each trial (the experimental subjects are described in Tables 1 and 2). Voles used in the trials were predator-naive and originated from laboratory stocks established between 1988-1991. The weasels were caught from southern or western Finland, and had been kept in captivity for 3-18 months. Weasels were fed with live mice and voles during their captivity. To standardize the hunting motivation of the weasels, they were not fed with new prey individuals for 24 hours before each trial, but they typically had unconsumed parts of previous prey individuals during this period. One weasel took part in only one trial per day.

Experiments were carried out on an indoor octagonal polywood arena (diameter $2.20 \mathrm{~m}$, height 1 $\mathrm{m}$ ) with natural light and temperature conditions. The arena was located in the unheated windowed attic of the Department of Ecology and Systematics in Helsinki. Eight non-transparent plastic boxes with a glass roof (size $20 \times 28 \times 37 \mathrm{~cm}$ ), one on each side of the arena, were connected to the arena with a $50 \mathrm{~cm}$ non-transparent plastic tube (diameter $5.5 \mathrm{~cm}$, height from the floor $7 \mathrm{~cm}$ ). These boxes housed the prey individuals during the experiments. Weasels in the experiment could not see a vole in a box from the arena. Wood chips and fiber were provided as bedding material and shelter in the boxes. For the weasel, a polywood nest box (size $16 \times 31 \times 31 \mathrm{~cm}$ with a $5 \mathrm{~cm}$ opening in the middle of the roof) with wood fiber was placed in the middle of the arena. The arena was covered with 12 $\mathrm{mm}$ metal-wired mesh.

Table 1. Least weasels used in the experiments. $\mathrm{F}$ - female, $\mathrm{M}$ - male.

\begin{tabular}{lccccccccc}
\hline \multicolumn{1}{c}{ Weasel number: } & 1 & 2 & 3 & 4 & 5 & 6 & 7 & 8 & 10 \\
\hline Sex & $\mathrm{F}$ & $\mathrm{F}$ & $\mathrm{F}$ & $\mathrm{F}$ & $\mathrm{M}$ & $\mathrm{M}$ & $\mathrm{M}$ & $\mathrm{M}$ & $\mathrm{M}$ \\
Weight (g) & 40 & 60 & 40 & 40 & 80 & 80 & 60 & 100 & 60 \\
Months in captivity & 3 & 18 & 7 & 6 & 4 & 16 & 12 & 5 & 3 \\
\hline
\end{tabular}

Table 2. Voles used in the experiments.

\begin{tabular}{|c|c|c|c|}
\hline \multirow{3}{*}{$\begin{array}{r}\text { Species: } \\
\text { Sex: } \\
\text { Age: }\end{array}$} & \multicolumn{2}{|c|}{ Clethrionomys glareolus } & \multirow{3}{*}{$\begin{array}{c}\text { Microtus agresti } \\
\begin{array}{c}\text { Females } \\
\text { adult }\end{array}\end{array}$} \\
\hline & \multicolumn{2}{|c|}{ Females } & \\
\hline & juvenile & adult & \\
\hline Average weight (g) & 12 & 22 & 36 \\
\hline$n$ & 112 & 338 & 286 \\
\hline
\end{tabular}


In the beginning of each trial, two individuals of either different prey species or of the same species but of different ages were placed in the plastic boxes one hour before the start of the experiment in order to scent the respective boxes with vole smell. During this one-hour period the boxes with voles were disconnected from the arena to prevent voles from entering the arena. The positions of the two boxes, among the 8 possible boxes, were selected at random. To start the trial, the vole boxes were connected to the arena and a weasel was released from the nest box in the middle of the arena. During the 15-minute trial, we recorded the order in which the weasel inspected the holes leading to the prey boxes, the finding order of the prey, the killing order, and the eating preference. The general hunting behaviour of the weasel was also observed during each trial. In addition, the same combination of prey individuals was offered to the weasel in metal-wired Ugglan live traps when the animal was removed from the arena, by setting two live traps with voles side by side in the arena (arena traps). Similar prey combinations and similar traps were also used irregularly when the home cages of the weasels were cleaned (cage traps). After every trial the arena, the boxes and the traps were thoroughly washed with detergent normally used in animal housing. Following cleaning, the arena, the boxes and the traps were left to dry for several hours (usually over night) before the next trial.

We compared the observed and expected frequencies of different elements in weasels' hunting behaviour with $\chi^{2}$-statistics. The results were further analyzed with three-dimensional contingency tables (log-linear models) to test for possible interactions among the different stages in the weasels' hunting behaviour. For example, a model K,FE would indicate that the finding order of the prey (F) affects the eating preference of the predator (E), but the killing order of the prey $(\mathrm{K})$ does not depend on the finding order and it does not affect the eating preference.

\section{Results}

All weasels easily learned the experimental setup after a couple of trials. Following learning, weasels started prey searching sooner than during the first trials. When the weasel had been released to the arena, it inspected the entry holes to vole boxes either systematically or randomly. The inspection behaviour was considered to be systematic if the weasel visited holes from the first one it encountered to either direction in a numerical order. In some cases the weasel appeared to start to inspect the holes from the one in which it had found prey in a previous trial. Both sexes showed a tendency to systematical inspection of entry holes. In the pooled data, in 99 of 168 cases weasels inspected entry holes systematically $\left(\chi^{2}=2.7, p=0.1\right)$. Only in the juvenile - adult bank vole trials, the sexes differed significantly in their inspection behaviour $\left(\chi^{2}=8.9, p=0.003\right)$, females showing more systematic search.

After locating the prey, the weasel either killed the prey immediately or continued to the next hole. There was no difference between the sexes in killing behaviour, and both sexes commonly continued searching after locating the first prey before killing it. In the pooled data, in 108 of 168 cases weasels continued the search $\left(\chi^{2}=7.0, p=0.008\right)$. The weasel used neck-biting to kill the prey, as described by eg King (1989). After killing both prey individuals, the weasel usually transferred the carcasses to one of the eight plastic boxes (not necessarily either one of the original two prey boxes), or to its nest box, and consumed the prey later. 
In most cases only one of the two prey individuals was eaten. All weasels started to eat the prey from the head region, and in many cases the whole prey individual was consumed. In all trials both prey individuals were killed during the trial.

\section{Bank vole - field vole trials}

Male weasels found the bank vole and the field vole equally often as the first prey, but females found the field vole more often first (Table 3). There was, however, no statistically significant difference between the sexes in the finding order of the two prey species. All males preferred killing the bank vole first independent of the finding order $(p=0.03)$, whereas females seemed to select the first prey to kill randomly (Table 3 ). The difference in the killing order between males and females was statistically significant (pooled data, $\chi^{2}=4.3, p=0.04$ ). Females very strongly preferred the bank vole when eating the prey after both prey individuals had been killed $(p=0.003$ ). With one exception (number 10), males also preferred bank voles as the prey to eat, though not as strongly as females (Table 3). (When removed from the arena, male number 10 exceptionally selected field vole-baited traps). The difference in the eating preference between females and males was statistically significant $\left(\chi^{2}=8.4, p=0.004\right)$. Males (except male number 10) and females showed no selection between traps baited with either species neither when removed from the arena (in 25 of 55 cases weasels selected bank vole-baited trap) nor when entering a trap placed in their own cage (in 26 of 38 cases weasels selected a bank vole-baited trap).

We analyzed possible interactions between the different stages in the weasels' hunting behaviour with log-linear models. Because there were differences between the sexes in the one-dimensional model we analyzed the sexes separately. In a model including the finding order, the killing order, and the eating preference,

Table 3. Bank vole - field vole experiments. Frequencies of finding, killing, and eating the prey first ( $n$ - number of replications).

\begin{tabular}{lrrlll}
\hline Weasel response & Bank vole & Field vole & $n$ & $\chi^{2}$ & $p$ \\
\hline Male weasels & & & & & \\
$\quad$ Found first & 24 & 25 & 49 & 0.01 & $\mathrm{~ns}$ \\
Found and killed first & 16 & 6 & 22 & 2.4 & $\mathrm{~ns}$ \\
Found second, killed first & 19 & 8 & 27 & 2.3 & $\mathrm{~ns}$ \\
Killed first, pooled & 35 & 14 & 49 & 4.8 & 0.03 \\
Eaten first & 20 & 16 & 36 & 0.2 & $\mathrm{~ns}$ \\
Female weasels & & & & & \\
Found first & 11 & 20 & 31 & 1.3 & $\mathrm{~ns}$ \\
Found and killed first & 8 & 13 & 21 & 0.9 & $\mathrm{~ns}$ \\
Found second, killed first & 7 & 3 & 10 & 0.8 & $\mathrm{~ns}$ \\
Killed first, pooled & 15 & 16 & 31 & 0.02 & $\mathrm{~ns}$ \\
Eaten first & 17 & 1 & 18 & 8.9 & 0.003 \\
\hline
\end{tabular}


Table 4. Best three-dimensional log-linear models for the bank vole - field vole experiments (see Table 3 ) and for the juvenile - adult bank vole experiments (see Table 5). Symbols: S - sex, F - finding order, K - killing order, E - eating preference.

\begin{tabular}{|c|c|c|c|c|}
\hline Model & Sex of weasels & df & $\mathrm{G}^{2}$ & $p$ \\
\hline \multicolumn{5}{|c|}{ Bank vole - field vole experiments: } \\
\hline (1) F, K, E & female & 4 & 7.64 & 0.106 \\
\hline (2) $\mathrm{K}, \mathrm{FE}$ & male & 3 & 0.12 & 0.989 \\
\hline \multicolumn{5}{|c|}{ Juvenile - adult bank vole experiments: } \\
\hline (3) S, F, K & pooled & 4 & 0.29 & 0.991 \\
\hline (4) S, K, E & pooled & 4 & 3.72 & 0.443 \\
\hline
\end{tabular}

there was no interaction between any of the factors in female weasels (Table 4: Model 1). The model does not, however, fit especially well the data. In male weasels, however, there was an interaction between the finding order of the prey and the eating preference (Table 4: Model 2), such that the prey found first, but not necessarily killed first, was usually eaten first. On the other hand, the finding order seemed not to determine the order in which prey individuals were killed by male weasels, and the killing order of the prey had no effect on the eating preference.

In summary, male weasels prefered bank voles when hunting (killing order), whereas females showed no such preference but preferred to eat the bank vole first. Female weasels selected the prey individual to consume after both prey

Table 5. Juvenile - adult bank vole experiments. Frequencies of finding, killing and eating the prey first ( $n$ - number of replications).

\begin{tabular}{lrrrrl}
\hline \multirow{2}{*}{ Weasel response } & \multicolumn{2}{c}{ Bank voles } & & & \\
\cline { 2 - 3 } & Adults & Juveniles & & $\chi^{2}$ & $\mathrm{p}$ \\
\hline Male weasels & & & & & \\
$\quad$ Found first & 25 & 15 & 40 & 1.3 & $\mathrm{~ns}$ \\
Found and killed first & 15 & 8 & 23 & 1.1 & $\mathrm{~ns}$ \\
Found second, killed first & 7 & 10 & 17 & 0.3 & $\mathrm{~ns}$ \\
Killed first, pooled & 22 & 18 & 40 & 0.2 & $\mathrm{~ns}$ \\
Eaten first & 4 & 28 & 32 & 10.5 & 0.001 \\
Female weasels & & & & & \\
$\quad$ Found first & 10 & 8 & 18 & 0.1 & $\mathrm{~ns}$ \\
Found and killed first & 5 & 4 & 9 & 0.1 & $\mathrm{~ns}$ \\
Found second, killed first & 4 & 5 & 9 & 0.1 & $\mathrm{~ns}$ \\
Killed first, pooled & 9 & 9 & 18 & 0.0 & $\mathrm{~ns}$ \\
Eaten first & 4 & 10 & 14 & 1.3 & $\mathrm{~ns}$ \\
\hline
\end{tabular}


individuals had been killed. This selection was not affected by the earlier phases in females' hunting behaviour, finding and killing. Male weasels, in contrast, seemed to select the prey to consume already when locating prey individuals, which determined the eating order of the killed prey: the prey which was killed first was not necessarily eaten first.

\section{Juvenile - adult bank vole trials}

We found a preference for juvenile bank voles in both males and females as a first choice to eat but not to kill (Table 5). There was no difference in the killing order or in the eating preference between the sexes. Nor was there any preference of either sex to select traps baited with juvenile or adult bank voles (males selected a juvenile bank vole-baited trap 16 of 37, and females 9 of 16 cases). When analyzing the data with log-linear models, there were no interactions either between the sex, the finding order and the killing order (Table 4: Model 3), or between the sex, the killing order and the eating preference (Table 4: Model 4). In other words, it appears that though both male and female weasels preferred juvenile bank voles when eating the prey the choice was made after both prey individuals had been killed.

\section{Discussion}

Weasels have been generally described as opportunistic hunters (King 1989). An actively hunting predator with opportunistic behaviour and high energy demand (Huey and Pianka 1981) should attack and consume all suitable prey species. In our experiments, availability and abundance of the two prey types were always equal. In addition, prey individuals in these experiments had no possibility to escape, which may have changed predators' behaviour. Nonetheless, our observations on weasels' habit of often not killing both prey individuals immediately, male weasels' preference to kill the bank vole first, and females' preference to eat the bank vole first suggest some selection. Selection is also supported by our preliminary result from one experiment (P. Pekkarinen and J. Heikkilä, unpubl.): we failed to change the preference of one female by a two-week exclusive use of the non-preferred prey (field vole). This observation suggests consistent preference of bank voles at least by this particular female.

One possible explanation of the observed differences between the sexes is based on the difference in body size, which determines the killing power and hence the range of possible prey sizes for male and female weasels. However, owing to this difference in body size, there is also a difference in the energetic needs of male and female weasels. Gillingham (1984) and Moors (1977) have calculated the daily food requirements of weasels in captivity. According to Gillingham (1984), male weasels need on average $32 \mathrm{~g}$ food/day. If we assume that female weasels need about $70 \%$ of males' requirements (based on values for other small mustelid species in King 1989), the figure would be $23 \mathrm{~g}$ for females. According to Moors (1977), 
weasels need $0.35 \mathrm{~g}$ food/g body weight in 24 hours. In our case this would amount to $27 \mathrm{~g}$ for males and $16 \mathrm{~g}$ for females per day. In our experiments the average weight of adult bank voles was $22 \mathrm{~g}$ and of field voles $36 \mathrm{~g}$. Therefore, to satisfy the daily food requirements, a bank vole would appear to be sufficient for females but too small for males. The observation that females always ate the bank vole in the experiment, with one exception, but males showed no such preference, is thus consistent with the difference in the daily food requirements of the two sexes. It is not obvious how these results should be interpreted for field situations, but our findings suggest that the relationships between prey size and the predator's daily food requirement may play a role in their hunting behaviour.

The clear preference in both sexes to consume juvenile bank voles is consistent with the observations of Jędrzejewska and Jędrzejewski (1990). They observed that weasels primarily killed young voles, apparently because of the poorly developed antipredatory behaviour in young bank voles. In addition, prevalence of Taenia mustelae, a mustelid tapeworm, is lower in juvenile bank voles (Le Pesteur et al. 1992), suggesting that it may be less harmful for the weasel to eat juvenile than adult voles. Voles in our experiments had no opportunity to escape, which may explain the random killing order of juvenile and adult bank voles. The fact that weasels killed all the prey individuals in the experiment is consistent with the surplus killing behaviour common in mustelids (Oksanen et al. 1985, Jędrzejewska and Jędrzejewski 1989), but in this case it probably also reflects the small scale experimental conditions. Predators are generally expected to assess, in addition to the energetic value of the prey, possible risks related to hunting. Especially female least weasels, being the very smallest mammalian predators with high energy demands, face this problem very acutely. Because they have relatively greater energy needs for maintenance than males, females should take greater risks than males in securing their daily meal. From the weasels' point of view, however, adult bank voles and adult field voles probably pose equal risks to the hunting predator, and the risk of hurting itself while attacking these two prey species is probably small. According to King (1989), all weasels, if necessary, are capable of killing prey larger than themselves. Derting (1989), however, observed that weasels had difficulties in biting and controlling prey weighing $60 \mathrm{~g}$. In our preliminary experiment (P. Pekkarinen and J. Heikkilä, unpubl.) with field and root voles, only the male weasel left some root voles alive in the experiment (in the experiment all root voles were females and weighed on average $53 \mathrm{~g}$ ).

The sensitive dependence of succesful breeding by least weasels on the abundance of Microtus voles has been discussed by Henttonen (1987). One major difference between Clehrionomys and Microtus species is the social structure of their populations. In the field vole, females are not territorial, but occur instead in dense aggregations with large numbers of individuals in suitable habitats. In the bank vole, females are territorial and defend large home ranges, and consequently population density remains generally at a much lower level than in the field vole (Henttonen 1987). From the weasels' point of view, the difference in density makes 
an important difference, and must likely explain why Microtus is "preferred" in the field (eg Hanski and Henttonen 1996).

In conclusion, we found an "intrinsic" preference of weasels to bank voles either in killing (males) or in eating the prey (females). Both sexes preferred to eat a juvenile bank vole first when they had a choice between a juvenile and an adult vole. Additionally, the observation that Taenia mustelae, a mustelid tapeworm, is more common in bank voles than in other vole species (Le Pesteur et al. 1992, V. Haukisalmi, pers. comm.) suggests that bank voles are often consumed. Le Pesteur et al. (1992) proposes that the high prevalence of T. mustelae in bank voles could be related to the preference of mustelids for bank vole habitats, with generally more cover than in many field vole habitats. All these results and observations suggest that weasels "intrinsically" prefer bank voles and that the proportion of this species should be much higher in the weasels' diet. The problem, for the weasel, however, is the social structure of bank vole populations (eg Henttonen 1987): the density of bank voles is generally much lower than the density of field voles, and it may often be too low for breeding females. Additionally, the bank vole exhibits effective antipredatory behaviours (Jędrzejewska and Jędrzejewski 1990) that are lacking in the field vole. In the wild, then, the use of the two vole species is reversed where they occur together, and the field vole, though less preferred "intrinsically", suffers a higher rate of weasel predation.

Acknowledgements: We are grateful to I. Hanski, V. Haukisalmi, H. Henttonen, E. Korpimäki, H. Pietiäinen and three anonymous referees for comments on earlier versions of this paper. We thank S. Pietiläinen for providing juvenile bank voles and $\mathrm{H}$. Henttonen and $\mathrm{K}$. Norrdahl for providing the weasels. For the experiments we had the permission of the Local Committee on Animal Experiments of the Faculty of Science, University of Helsinki. The study was funded by a grant from the University of Helsinki to I. Hanski.

\section{References}

Day M. G. 1968. Food habits of British stoats (Mustela erminea) and weasels (Mustela nivalis). Journal of Zoology, London 55: 485-497.

Derting T. L. 1989. Prey selection and foraging characteristics of least weasels (Mustela nivalis) in the laboratory. The American Midland Naturalist 122: 394-400.

Erlinge S. 1974. Distribution, territoriality and numbers of the weasel Mustela nivalis in relation to prey abundance. Oikos 25: 308-314.

Erlinge S. 1975. Feeding habits of the weasel Mustela nivalis in relation to prey abundance. Oikos 26: 378-384

Erlinge S., Jonsson B. and Willstedt H. 1974. [Hunting method and prey selection of the least weasel]. Fauna och Flora 69: 95-101. [In Swedish with English summary]

Gillingham B. J. 1984. Meal size and feeding rate in the least weasel (Mustela nivalis). Journal of Mammalogy 65: 517-519.

Hanski I. and Henttonen H. 1996. Predation on competing rodent species: a simple explanation of complex patterns. Journal of Animal Ecology 65: 220-232.

Heikkilä J., Kaarsalo K., Mustonen O. and Pekkarinen P. 1993. Influence of predation risk on early development and maturation in three species of Clethrionomys voles. Annales Zoologici Fennici 30: $153-161$. 
Henttonen H. 1987. The impact of spacing behavior in microtine rodents on the dynamics of least weasels Mustela nivalis - a hypothesis. Oikos 50: 366-370.

Huey R. B. and Pianka E. R. 1981. Ecological consequences of foraging mode. Ecology 62: 991-999.

Jędrzejewska B. and Jędrzejewski W. 1989. Seasonal surplus killing as hunting strategy of the weasel Mustela nivalis - test of a hypothesis. Acta Theriologica 34: 347-359.

Jędrzejewska B. and Jędrzejewski W. 1990. Antipredatory behaviour of bank voles and prey choice of weasels - enclosure experiments. Annales Zoologici Fennici 27: 321-328.

Jędrzejewski W. and Jędrzejewska B. 1990. Effect of a predator's visit on the spatial distribution of bank voles: experiments with weasels. Canadian Journal of Zoology 68: 660-666.

Jędrzejewski W. and Jędrzejewska B. 1992. Hunting success of the weasel Mustela nivalis and escape tactics of forest rodents in Białowieża National Park. Acta Theriologica 37: 319-328.

Jędrzejewski W. and Jędrzejewska B. 1993. Predation on rodents in Białowieża primeval forest, Poland. Ecography 16: 47-64.

King C. 1989. The natural history of weasels and stoats. Christopher Helm, London: 1-253.

Korpimäki E. 1993. Regulation of multiannual vole cycles by density-dependent avian and mammalian predation? Oikos 66: 359-363.

Korpimäki E. and Norrdahl K. 1989. Avian and mammalian predators of shrews in Europe: regional differences, between-year and seasonal variation, and mortality due to predation. Annales Zoologici Fennici 26: 389-400.

Korpimäki E., Norrdahl K. and Rinta-Jaskari T. 1991. Responses of stoats and least weasels to fluctuating food abundances: is the low phase of the vole cycle due to mustelid predation? Oecologia 88: 552-561.

Korpimäki E., Koivunen V. and Hakkarainen H. 1996. Microhabitat use and behavior of voles under weasel and raptor predation risk: predator facilitation? Behavioral Ecology 7: 30-34.

Kytömäki J. and Kankaanrinta I-K. 1994. [Year '95]. Painosalama, Turku: 1-267. [In Finnish]

Le Pesteur M. H., Giraudoux P., Delattre P., Damange J. P. and Quere J. P. 1992. Spatiotemporal distribution of four species of cestodes in a landscape of mid-altitude mountains (Jura, France). Annales de Parasitologie Humaine et Comparee 67: 155-160.

Moors P. J. 1975. The food of weasels (Mustela nivalis) on farmland in north-east Scotland. Journal of Zoology, London 177: 455-461.

Moors P. J. 1977. Studies of the metabolism, food consumption and assimilation efficiency of a small carnivore, the weasel (Mustela nivalis L.). Oecologia 27: 185-202.

Myllymäki A. 1972. [Field vole]. [In: Suomen nisäkkäät I. L. Siivonen, ed]. Otava, Keuruu: 381-395. [In Finnish]

Norrdahl K. and Korpimäki E. 1993. Predation and interspecific competition in two Microtus voles. Oikos 67: 149-158.

Oksanen T., Oksanen L. and Fretwell S. 1985. Surplus killing in the hunting strategy of small predators. The American Naturalist 126: 328-346.

Rubina M. A. 1960. Some features of weasel (Mustela nivalis) ecology based on observations in the Moscow region. Byulleten Moskovskogo Obshchestva Ispytatelei Prirody: Otdel Biologii 65: 27-33.

Siivonen L. and Artimo A. 1972. [Bank vole]. [In: Suomen nisäkkäät I. L. Siivonen, ed]. Otava, Keuruu: 330-341. [In Finnish]

Tapper S. C. 1976. The diet of weasels, Mustela nivalis and stoats, Mustela erminea during early summer, in relation to predation on gamebirds. Journal of Zoology, London 179: 219-224.

Tapper S. 1979. The effect of fluctuating vole numbers (Microtus agrestis) on a population of weasels (Mustela nivalis) on farmland. Journal of Animal Ecology 48: 603-617.

Walker D. R. G. 1972. Observations on a collection of weasels (Mustela nivalis) from estates in south-west Hertfordshire. Journal of Zoology, London 166: 474-480.

Received 28 May 1996, accepted 15 March 1997. 